Human Ethology Bulletin 32 (2017)3: 1-2

Letter from the Editorial Board

\title{
EDITORIAL
}

\section{Colin Hendrie}

\author{
Editor in Chief
}

This edition marks a change in Editorship of HEB as Dr Elisabeth "Lisa" Oberzaucher steps down and I pick up the reins. As incoming Editor-in-Chief I would like to thank Lisa for the guidance she has given in helping to produce this jointly edited edition and to offer my heartfelt congratulations to her for the fine job she has done as Editor over the past five years. I would also very much like to thank Drs Susanne Schmehl and Kathrin Masuch for the vital work they have done behind the scenes in helping to produce each issue. ISHE intends for HEB to become a fully listed journal and the Bulletin has moved significantly nearer to this important landmark under Lisa's Editorship.

I would also like to add my voice to Lisa's (Oberzaucher, 2017) in acknowledging the work done by the Associate Editors, book review editor and all the anonymous reviewers. People's willingness to take on these roles is vital for the Bulletin to thrive and I look forward to working with everyone on the editorial team over the coming years.

As Editor I aim to continue Lisa's good work in encouraging authors to submit their work to HEB. The Bulletin is open to receiving all manner of ethologically orientated contributions including position papers, theoretical reviews, new hypotheses, as well as of course research papers reporting new data. The Human Ethology Bulletin offers high quality peer review and most importantly, open access publication that remains free to both reader and author.

Beyond publication per se, HEB also has the potential to facilitate the research process itself, particularly by bringing together researchers from around the world. One of the major criticisms levelled at university-based research has been the heavy reliance on Western, educated, industrialized, rich and democratic (WEIRD) participants (Henrich et al, 2010). 
ISHE counts amongst its membership a number of anthropologists who are often interested in specific populations, but for those that are not, WEIRD type issues can create significant problems. Many of these can however be avoided and addressed through collaboration and I hope to discuss with the Editorial Board ways in which cross-cultural collaborations can be facilitated through the Bulletin, whether this be through print or social media, and so compliment the role that ISHE meetings already play in this respect.

Finally, as ethologists we are all aware of the power applying Tinbergen's four questions brings to the analysis and understanding of a wide range of issues. In that spirit I will be inviting contributions to a series of articles, where the authors are asked to consider the advantages and disadvantages of bringing the ethological approach to bear on problems more usually addressed by other disciplines. The editorial team will also be glad to hear from those wishing to volunteer contributions. To example this, my co-authors and I have previously argued that progress in Psychiatry would be more readily forthcoming if a more ethologically based approach was used. We also contend that Psychiatry's failure to adopt this methodology, at least in the context of clinical trials, was one of main reasons why the antidepressant drug discovery process collapsed (Hendrie and Pickles, 2013). Similarly, many will have also wondered, from an ethological perspective, what the impact on Psychology and Evolutionary Psychology would have been had Tinbergen's comparative approach been adopted by those disciplines from the outset ...

\section{REFERENCES}

Hendrie, C., \& Pickles, A. (2013). The failure of the antidepressant drug discovery process is systemic. Journal of Psychopharmacology, 27(5), 407-416. DOI

Henrich, J., Heine, S. J., \& Norenzayan, A. (2010). The weirdest people in the world?. Behavioral and Brain Sciences, 33(2-3), 61-83. DOI

Oberzaucher E. (2017) Passing on the chair. Human Ethology Bulletin 32, 1- 4. DOI 